\title{
The Silviculture Conference Recent activities and accomplishments in silviculture in Québec
}

\author{
by Michel Tremblay
}

\section{Introduction}

I was delighted to accept the invitation to participate in this second national conference on silviculture and to speak to you about recent developments in silviculture in Québec.

The main focus of my speech today will be:

- The basic principles of Quebec's forest system;

- The reorientation of the forest regeneration method;

- The proposed forest protection strategy;

- Integrated resources management.

\section{Québec's Public Forest System: Basic Principles}

On December 19, 1986, Québec's National Assembly passed a bill that received assent as the Forest Act (1986, Chapter 108). This Act, which came into force on April 1, 1987, introduced a new forest system for Québec, abolishing a system that had been adopted more than a century before.

\section{A New Sharing of Responsibilities}

The new Act requires the Québec Government and the forest industry to share responsibility for the management and protection of forests in the public domain.

The State plans, standardizes, coordinates and controls public forest management activities, while the industry, in accordance with its contract with the Government, is required to comply with the Act and the regulations, to plan and carry out management activities and, with the Government, to contribute to forest protection.

\section{Multiple-use of the Forest Environment}

Québec gave itself the power to apply strict management standards so as to ensure the protection of the various forest resources as well as of specific sites which is essential to achieve multiple-use of forest environment.

In its role as manager of lands in the public domain, the Government has drawn up the land use plan, a cartographical document that identifies the potential of various territorial units, their respective uses and any sites requiring special protection (parks, ecological reserves, essential wildlife habitats, cultural and archeological sites, etc.). In addition to the map, the Government has made, for each site or resource to be protected, regulations to define specific management standards to be applied by everyone involved in public forest management. This philosophy forms the very base of the forest system.

\section{Compliance with the Sustained-yield Principle}

To replace the various forms of tenure or allocation existing before April 1, 1987, the Forest Act introduced a new type of management based on timber supply and forest management agreements or TSFMAs.

Head of the Service des techniques d'intervention forestière, ministère des Forêts.

Paper presented at the Silviculture Conference 93, Toronto, Ontario, September 1993.
The TSFMAs entitle holders to obtain an annual forest management permit to harvest a volume of round timber of one or several species on the forest land described in the agreements, in order to supply their wood processing plants. The holders undertake to fulfill their obligations under the Act and the agreements, and to carry out silvicultural treatments necessary to achieve the annual yields specified in the agreements for each area earmarked for forest production.

\section{Reorientation of the Forest Regeneration Method}

Our concerns here are softwood forests as we do not normally experience much difficulty with natural regeneration in our hardwood forests, as long as our tending methods are adapted to their structure and composition.

In our softwood forests, however, deficiencies sometimes have to be compensated to achieve satisfactory regeneration.

\section{Increased Reliance on Natural Regeneration}

Pre-harvest or post-harvest regeneration is best suited to the natural process. Generally speaking, it is also the best adapted to the site, and it occurs to an interesting degree on a large proportion of softwood harvesting areas. We will thus be mainly relying on this type of regeneration in the future, to ensure the renewal of our softwood stands.

Over the past five or six years, timber supply and forest management agreement holders have already made significant changes to their harvesting techniques. A felling technique known as «harvesting with advance-growth protection», almost unheard-of before 1987, is now used in more than half Québec's softwood harvesting areas. The Government is currently looking into the possibility of amending the regulations to make this technique compulsory in all harvesting areas.

Natural regeneration, where insufficient to meet production objectives, will be supplemented by reinforcement planting (more than 12 million seedlings were used for this purpose in 1993). Plantations, planting 1875 seedlings or more per hectare, will be established to help meet increased production objectives or where natural regeneration is too slow.

\section{The Proposed Forest Protection Strategy}

In February 1989, Québec's Council of Ministers decided to introduce a forest protection strategy. The aim of the strategy was to provide guidelines for achieving sustained timber yields and suggest ways and means of reducing pesticide use in line with the August 1989 policy statement on pesticide use in forests.

To take account of the concerns expressed by the population at public hearings on planned aerial insecticide spraying in forests, the Council of Ministers asked the Bureau d'audiences publiques sur l'environnement (BAPE) to carry out hearings on the draft strategy. The hearings took place in 1991, in a series of 21 public sittings held throughout Québec.

The 73 proposals retained in the BAPE report were rigorously analyzed by the ministère des Forêts, and a memoran- 
dum was subsequently submitted to the Council of Ministers to obtain its approval for the suggested guidelines of the Government's forest protection strategy. The Council of Ministers has not yet reached a decision.

Otherwise, I propose to you a reflexion on some elements that could be allowed to reach previously mentioned targets.

\section{Preventive Silviculture}

One of the department's proposals is concerned with improving the resistance of timber stands to insects and diseases by reducing the relative importance of species vulnerable to these disturbances and by improving the health of standing trees. The department has also proposed preferential harvesting of forests which, because of their characteristics, would require significant protection programs during future insect epidemics. To eliminate phytocide use, the ministère des Forêts has proposed the following measures:

- Annual planting of 40 million large seedlings, beginning in 1997; large seedlings have a minimum height of $40 \mathrm{~cm}$, a neck diameter of around $6 \mathrm{~mm}$ and an H/D ratio between 6 and $7 ;$

- Protection of young trees growing under mature forest canopies during harvesting operations;

- Planting soon after harvesting on areas where it is required; the maximum period suggested is two years;

- Mechanical clearing of softwood regeneration growing under hardwood canopies;

- Adjustment of harvesting methods and techniques to provide greater protection for wet lands and thin soil covers.

\section{Pesticide Use}

\section{- Insecticides}

With respect to insecticide use, the ministère des Forêts has made the following proposals:

- Exclusive use of Bacillus thuringiensis (B.t.) or other biological insecticides in the fight against the spruce budworm;

- Analysis of all available means for controlling other insects. The product or products to be used would be selected on the basis of their safety and performance in environmental and forest terms.

In fact, since 1992 the Société de protection des forêts contre les insectes has used only B.t. as an insecticide.

\section{Phytocides}

The ministère des Forêts recommend the elimination of chemical phytocides over a ten-year period. This period reflects the time required for the effects of the preventive measures provided for in the phytocide elimination strategy to be felt. The principal measures recommended are the production and planting of large seedlings, changes in harvesting procedures and forest management, and the acceleration of research into the development of biological products.

Although the plan to abandon phytocides within ten years is very ambitious, it only partly satisfies the demands of citizens, who would like to see them disappear more quickly. Forest managers, on the other hand, would like to be able to go on using them.

I think you will agree that future discussions on this sensitive issue are likely to be interesting!

\section{Distribution of Harvesting Areas}

With respect to the time-space aspects of harvesting area distribution, the ministère des Forêts is considering the following proposals:

- To avoid juxtaposed harvesting areas until the regeneration in the harvested area reaches a certain height class;

- Preservation of the essential elements of wildlife habitats;

- Constant preservation of a certain percentage of the forest canopy, determined by the type of stands, on each territorial reference unit;

- Reduction of the current maximum clearcut area of 250 hectares.

\section{Research and Development}

The ministère des Forêts also suggests an increase in research into prevention and elimination. In our view, it is important to achieve a better understanding of certain silvicultural practices in order to minimize the problems caused by competing vegetation, insects and diseases and by the fragility of some environments.

Forestry research is already focused on the dynamics of competing vegetation, the testing of different types of mulch, and mechanical maintenance methods. New production and planting methods for large seedlings are also being studied: storage conditions, seedling nutrition management, fertilization schedules and container types.

Through research into the dynamics of spruce budworm populations, we hope to be able to forecast the insect's migrations more accurately. The results obtained in the development of new, more effective types of Bacillus thuringiensis (B.t.) are extremely encouraging, and will almost certainly bring about a reduction in the amount of insecticide needed.

\section{Integrated Resources Management}

In 1991, the Québec Government launched a project to develop integrated forest resources management. The aim of the project is to trigger changes in attitudes among managers, users and the population in general.

The concept of integrated resources management is easy to understand in forestry terms. It consists in bringing the characteristics of the different environmental elements, including the forest itself, wildlife and water resources, together under the same umbrella of concern in order to measure their interdependencies and avoid situations where action in one field leads to problems in others. However, while the concept may be easy to understand, it is extremely difficult to put into practice.

\section{Conclusion}

This, then, was a brief overview of recent developments in silviculture in Quebec. As we have seen, the approach to which Québec is now firmly committed will enable it to use its forest resources in a way that respects modern environmental concerns, while allowing the forest-related economic activities to flourish. 